\title{
Lead deposition from mobile sources: A case study of Ndola-Kitwe dual carriage highway
}

\author{
Cuthbert Casey Makondo ${ }^{1}$, Jhonnah Mundike ${ }^{2}$, Phenny Mwaanga ${ }^{1}$ \\ ${ }^{1}$ Department of Environmental Engineering, Copperbelt University, SMMS, Kitwe, Zambia \\ ${ }^{2}$ Department of Process Engineering, Stellenbosch University, Stellenbosch (RSA)
}

\section{Email address:}

cuthbert.makondo@cbu.ac.zm (C. Makondo),18251366@sun.ac.za (J. Mundike),phenny.mwaanga@cbu.ac.zm (P. Mwaanga)

\section{To cite this article:}

Cuthbert Casey Makondo, Jhonnah Mundike, Phenny Mwaanga. Lead Deposition from Mobile Sources: A Case Study of Ndola-Kitwe Dual Carriage Highway. American Journal of Environmental Protection. Vol. 2, No. 6, 2013, pp. 128-133.

doi: 10.11648/j.ajep.20130206.12

\begin{abstract}
The main purpose of this study was to investigate levels of lead contamination from past use of leaded fuel in motor vehicles along the Kitwe-Ndola dual-carriage way (high way), in the Copperbelt Province of Zambia. The study was conducted over a period of seven months (April to November, 2012). Following the phasing out of leaded fuel in Zambia in 2010, the question that needed addressing was "how much of the lead on the surface and sub-surface levels in soils was due to leaded fuel influence?" To answer this question, sixteen (16) sampling points were set from which 32 samples were collected to analyze for soil lead levels along the highway (HWY). The selection of the study area and consequently sampling points was based either on heavy traffic, economic activities or population density along the HWY. The samples were collected at different depths $(0.05 \mathrm{~m}$ and $0.50 \mathrm{~m})$ and varying distances $(5 \mathrm{~m}$ and $50 \mathrm{~m})$ from the HWY at the selected sampling points. The collected samples were then analyzed for the lead content in triplicates. The results showed that concentrations reduced with distance from the HWY and concentrations were generally higher on the surface $(0.05 \mathrm{~m})$ than at the bottom $(0.50 \mathrm{~m})$. The results further showed higher concentrations of lead at points where vehicles generally slowed down along the HWY. This was particularly the case with the police check point $(611 \mathrm{ppm})$ which had the highest levels of lead contamination on the soils. The results of this study revealed that there is lead contamination of soils along the KitweNdola HWY which emanated from mobile sources. It could therefore be seen that two (2) years after the phasing out of leaded fuel in Zambia, the soil lead levels remain influenced by the past use of leaded fuel.
\end{abstract}

Keywords: Leaded Fuel, Mobile Sources, Soil Contamination

\section{Introduction}

\subsection{History of Leaded Fuel Use in Zambia}

Lead has been used in motor engine gasoline (fuel) globally as "tetraethyl lead" from as early as the 1920s. In Zambia, though the exact year leaded fuel was first used in automobiles is not very clear, it has been associated with the first gasoline powered machine that drove over the Zambian roads during the Federal Government in the 1940s [1]. Tetraethyl lead (TEL) was used in early model car engines as an anti-knock agent to help reduce engine knocking, boost gasoline octane rating, and help prevent wear-and-tear on valve-seats within the engine [2]. However, due to concerns over environmental and health risks, this type of fuel was slowly phased out globally starting in the late 1970's in the United States of America and was banned in that country altogether on all on-road vehicles in 1995[3];[4].

The move to phase out leaded gasoline (fuel) in Southern African Development Community (SADC) gained momentum after the 2002 World Summit on Sustainable Development (WSSD) in South Africa, which resulted in the launch of a Partnership for Clean Fuels and Vehicles[5]. The partnership seeks to improve among other things, air quality across the developing world by encouraging the deployment of cleaner technologies, and fuels, such as unleaded and low sulphur petrol and diesel, and improved catalytic converters that can significantly reduce exhaust fumes [5]. Progress towards a complete phase-out of leaded fuel in the SADC region has however been notably slow, with most countries reporting challenges for the switch to the "cleaner" fuels.

In Zambia, following the SADC agreement by member 
countries to phase out leaded gasoline in 2002, the government of the Republic of Zambia decided to set a target of phasing out of leaded gasoline by $31^{\text {st }}$ April 2008 [1]. This commitment was also driven by the evidence of serious human health and environmental impacts of lead observable in Kabwe town where mining of this metal has been going on from 1909 to 1994[6]. In order to promote public health and clean environment, and in line with the modern trends in the automobile industry, all petroleum stakeholders in Zambia would from 1st April 2008, provide a complete range of lead-free gasoline to suit all motorvehicles [1] ; [5]. Two types of unleaded gasoline, namely unleaded petrol, and lead replacement petrol were available on the Zambian market by $1^{\text {st }}$ April 2008 . However, due to lack of stringent regulatory enforcement, most filling stations continued with the selling of leaded gasoline in the name of clearing old stock [7];[8].

\section{Site Description}

Ndola-Kitwe dual-carriage way is a busy highway covering a stretch of $60 \mathrm{~km}$ between the two towns of Kitwe and Ndola. The HWY is surrounded by human settlements on both sides. This HWY also connects Luanshya and Kitwe, some $48 \mathrm{~km}$ away, branching off to the west on the way to Ndola. The HWY is also a link between Ndola and Mufulira through Kitwe. The other mining towns of Chingola, Chililabombwe and further on, Solwezi, have added to the busy traffic along the HWY. Furthermore, all vehicles from Lusaka and further south of Zambia are linked to Kitwe through this HWY. There are small-scale farms and a few commercial farms along the HWY, where various crops are grown, with some domestic animals seen grazing in fenced paddocks. Due to the busy traffic schedule along the HWY, the area selected presents a representative case study in terms of lead contamination from mobile sources (traffic air emissions).

Sampling points were randomly picked along the HWY, covering a stretch of about $5 \mathrm{~km}$ (see figure 1 below).

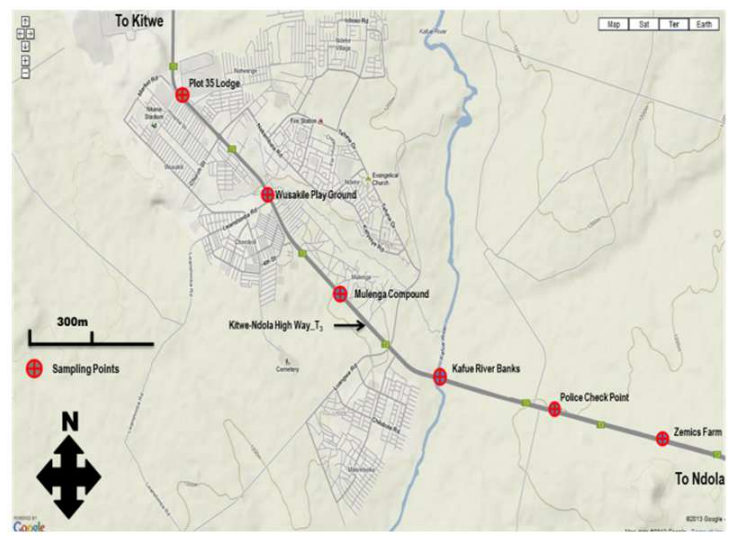

Figure 1: Location of study area

The sampling areas were located between Wusakile Township and Zemics Lodge turn-off, about a kilometer before Kanfinsa/Mwekera turn-off. The sampling points were set at a distance of $5 \mathrm{~m}$ and $50 \mathrm{~m}$ away from the HWY. At each sampling point, soil samples were collected at the surface $(0.05 \mathrm{~m}$ deep) and at the bottom ( $0.5 \mathrm{~m}$ deep).

The first two sampling points were at Lodge 35 at both sides of the HWY (WC lodge side and WC opposite lodge), followed by the third sampling point at the playground (WC playground) near the traffic roundabout. The distance between the first two sampling points and the third is about $500 \mathrm{~m}$. The fourth and fifth sampling points were around Mulenga Compound (MC) on both sides of the HWY. The sixth sampling point was by the bank of the Kafue River. The seventh sampling point was at Police Check-point, about $300 \mathrm{~m}$ away from the banks of the Kafue River. The last sampling point was at Zemics Lodge turn-off, about 2 $\mathrm{km}$ away from the Police Check-point, just before Kanfinsa/Mwekera turn-off.

\section{Materials and Methods}

\subsection{Materials and Equipment}

The following materials and equipment were used in this study: Hand auger, measuring tape $(100 \mathrm{~m})$, permanent markers, and high density polyethylene bags were used in the collection of samples. The oven was used for drying samples, The pulverizer was used in sample pulverization, wire mesh sieve and shaker were used in getting the required sample particle size $(850 \mu \mathrm{m})$, Analytical balance was used for weighing out the appropriate sample weights, hot plate was used for digesting the samples, Nitric acid (Analar) was used for decomposing samples, distilled water was used for sample dilution, 540 Whatmann filter paper was used for filtration of samples, Atomic Absorption Spectrophotometer (AAS; Analyst-200 Perkin-Elmer model) was used for the analysis of the samples.

\subsection{Highway Survey}

The HWY was surveyed to establish the pattern of traffic activities. There are certain points along the HWY where vehicles slow down such as the traffic roundabout, bus stop, filling stations, traffic police check-point and side road junctions. Human activities along the HWY (settlements, playground, crop farming, and animal farming) helped in selecting sampling points.

\subsection{Soil Sampling}

At each sampling site, two sampling points were established at $5 \mathrm{~m}$ and $50 \mathrm{~m}$ away from the HWY. Using the auger, surface soil sample of about $500 \mathrm{~g}$ was collected at a depth of $0.05 \mathrm{~m}(5 \mathrm{~cm})$ and placed into polyethylene sampling bag and then labeled with a permanent marker. The auger was further used to drill deep into the soil up to $0.5 \mathrm{~m}(50 \mathrm{~cm})$ to get another sample of about $500 \mathrm{~g}$ at this depth and was placed into a sampling bag, labeled with a marker, sealed and then placed in a carrying container for laboratory analysis. 
The above procedure was repeated for all other sampling points.

\subsection{Sample Preparation and Analysis}

The $500 \mathrm{~g}$ of the sampled soil was dried at $105^{\circ} \mathrm{C}$ for one hour to remove moisture. The soil sample was then cooled and ground to fine particles in a pulverizer for 3 minutes. The pulverized sample was sieved through a wire-mesh sieve shaker at 20-mesh $(850 \mu \mathrm{m})$.

$1 \mathrm{~g}$ of the sieved sample was accurately weighed on an analytical balance and placed into a $250 \mathrm{ml}$ beaker. Then 30 $\mathrm{ml}$ of concentrated analytical grade (Analar) nitric acid was added to the sample in a $250 \mathrm{ml}$ beaker and was then covered with a watch glass and then heated on a hot plate to the final volume of about $10 \mathrm{ml}$ (for about 30 minutes). Then distilled water was added to the resultant solution (10 $\mathrm{ml}$ volume) up to a final volume of $50 \mathrm{ml}$. This solution was further boiled on a hot plate for 5 minutes in order to dissolve the salts. Thereafter, the solution was cooled to room temperature and filtered through a 540 Whatmann filter paper into a $100 \mathrm{ml}$ volumetric flask. Distilled water was added up to the mark of the $100 \mathrm{ml}$ volumetric flask.

The resultant solution was taken for lead determination on an Atomic Absorption Spectrophotometer (AAS) (model Perkin Elmer Analyst-200). The results in parts per million (ppm) were determined using lead calibration standards. For quality control purposes, sample blanks were spiked with lead standards and recoveries calculated ranged from $99 \%-102 \%$.

\section{Results and Discussion}

The results of this study showed an interesting trend (table 1). For each sampling point, the lead concentrations (ppm) on the surface $(0.05 \mathrm{~m})$ were observed to be higher than at the subsurface $(0.50 \mathrm{~m})$. Similarly, the lead concentrations were observed to be reducing as distance from the HWY increased. Clearly the trends (see figure 2) showed that the highest lead concentration was at the police check point, interestingly, this is the point where all motor vehicles slowed down.

Table 1: lead Soil Concentration in ppm

\begin{tabular}{|c|c|c|c|c|}
\hline \multirow{2}{*}{$\begin{array}{l}\text { Sampling point } \\
\text { or site } \\
\text { (name) }\end{array}$} & \multicolumn{2}{|c|}{5 m away from $H W Y$} & \multicolumn{2}{|c|}{$50 \mathrm{~m}$ away from HWY } \\
\hline & $\begin{array}{l}\text { Surface } \\
(0-0.05 \mathrm{~m})\end{array}$ & Bottom $(0.5 \mathrm{~m})$ & $\begin{array}{l}\text { Surface } \\
(0-0.05 \mathrm{~m})\end{array}$ & $\begin{array}{l}\text { Bottom } \\
(0.5 \mathrm{~m})\end{array}$ \\
\hline Zemics & 333 & 194 & 240 & 109 \\
\hline Kafue River & 465 & 361 & 310 & 184 \\
\hline MC left Ndola & 447 & 370 & 353 & 273 \\
\hline MC right Ndola & 354 & 291 & 188 & 170 \\
\hline WC lodge side & 461 & 331 & 193 & 165 \\
\hline WC opposite lodge & 358 & 260 & 390 & 287 \\
\hline WC play ground & 463 & 311 & 360 & 206 \\
\hline Police check point & 611 & 386 & 459 & 286 \\
\hline
\end{tabular}

MC left Ndola means Mulenga compound on the left side of the HWY, MC right Ndola means Mulenga compound on the right side of the HWY, WC lodge side means Wusakile compound on the right side of HWY and WC lodge side means Wusakile compound on the left side of HWY and HWY means High way

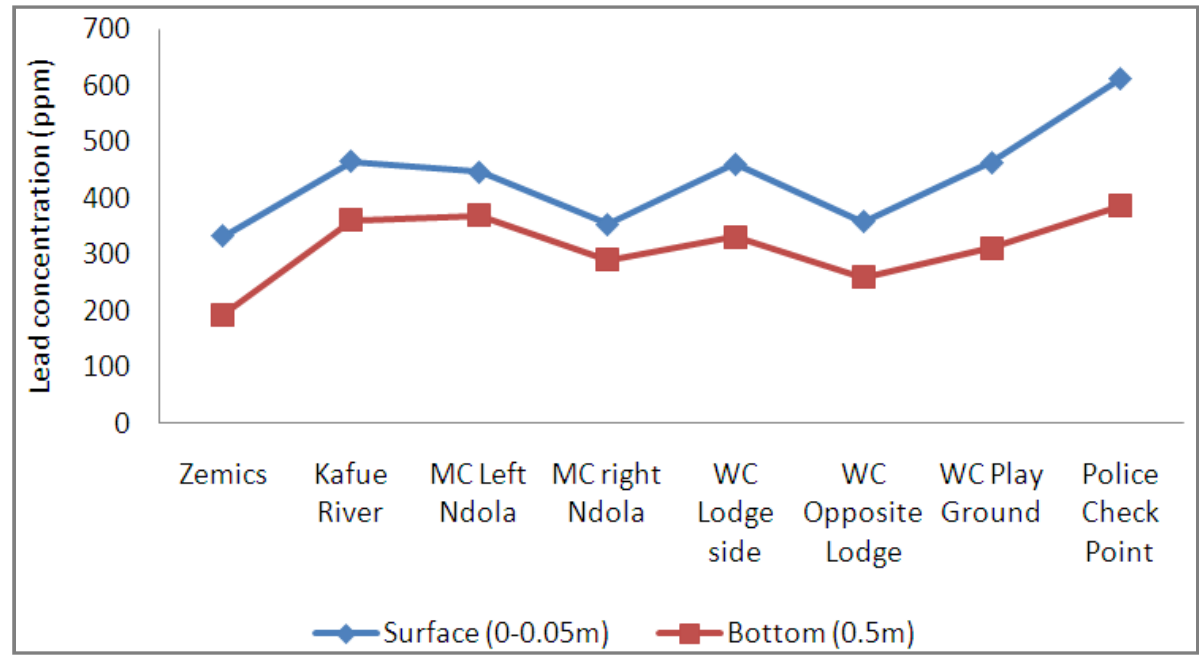

Figure 2: general surface and sub-surface variation of lead concentrations along the HWY 


\subsection{Vertical and Horizontal Gradient Variations}

A critical examination of the results trends indicated that the data could be grouped into four categories. That is (a) vertical variation $5 \mathrm{~m}$ from the HWY (figure 3 ), (b) vertical variation $50 \mathrm{~m}$ from the HWY (figure 4), (c) horizontal variation for surface $(0.05 \mathrm{~m})$ samples taken at $5 \mathrm{~m}$ and $50 \mathrm{~m}$ away from the HWY (figure 5), and (d) horizontal variation for bottom $(0.50 \mathrm{~m})$ samples taken at $5 \mathrm{~m}$ and $50 \mathrm{~m}$ away from the HWY (figure 6). The extent of change in lead concentration between the levels in each category was expressed as the fractional gradient reduction, which was calculated as the difference in lead concentration between the two levels in each category divided by the level with higher lead concentration in that category.

Although for some sampling points such as the Wusakile compound lodge (WC lodge) and the Mulenga Compound (MC), samples were collected on both sides of the HWY (i.e. right and left sides),it was however, difficult to collect samples on both sides of the HWY for other sampling points on account of inaccessibility.

The General trends of results for all the categories showed that the lead concentrations for all sampling sites close $(5 \mathrm{~m})$ to the HWY were higher than those further $(50 \mathrm{~m})$ away from the HWY. This was the case for both surface $(0.05 \mathrm{~m})$ and the bottom $(0.50 \mathrm{~m})$ samples (see figures 3 to 6).The trends displayed by the results could be attributed to the deposition from traffic as the source of this lead. Interestingly, notably higher concentrations of lead were observed at points where traffic slowed down. This was particularly the case at the police check point, which had the highest concentrations of up to $611 \mathrm{ppm}$. Given that there are traffic police officers manning this point for more than 8 hours a day, the health implication of having high concentrations of lead at the point may be huge.

Traffic officers who monitor road traffic at this particular point are constantly inhaling exhaust fumes from morning to evening. As the result seem to suggest, that cars release more exhausts as they slow down and that these exhaust find a way of settling down on surfaces, it is possible that a relatively high level of the same may be inhaled as it settles. It is known that between $30-45 \%$ of lead inhaled is returned by the body[9]; [10]. This therefore implies that the traffic police officers found at the check point were at a higher risk of lead poisoning. This conclusion is consistent with the available pharmacokinetic data, which indicate that lead is absorbed by humans following inhalation of particulate lead in ambient air and ingestion of contaminated foods, drinking water and soil [11]; [12]; [13].

The results showing the vertical gradient variation in the lead concentrations(figures 3and 4)consistently showed that the lead concentrations were highest at the police check point. Similar results were also observed for the horizontal gradient variation for figure 5 . However, the results of the horizontal gradient variation for sub-surface $(0.50 \mathrm{~m}$ depth) samples (figure 6)showed that the lead concentration at the police check point, Kafue River and MC left to Ndola were not significantly different $(p>0.05)$. Although, it was difficult to explain this observation (results), this could probably point to the differences in leaching rates of lead through the sub-soils. Consistent with expectation, for all the graph categories, the data showed that the Zemics sampling point had the lowest lead concentration $(\mathrm{p}<0.05)$ among all the sampling points. This was attributed to the least influence this sampling point experienced from traffic. Visual observation revealed that among all sampling points within the area of study, Zemics was the only point where motor vehicles traveled at normal speed $(80 \mathrm{~km} / \mathrm{h})$. This further suggests that motor vehicles release less exhaust fumes when moving fast compared to when they slow down.

The levels of lead concentration observed at Zemics, for the surface samples (333ppm at $5 \mathrm{~m}$ away from HWYand $240 \mathrm{ppm}$ at $50 \mathrm{~m}$ away from HWY), though lower compared to the levels observed at other sampling points, could however, still be of concern especially that a variety of food crops such as bananas, groundnuts and maize are grown on the farms around this area. These crops/plants could absorb and concentrate lead levels and this could constitute an exposure pathway for humans, who consume the crops/plants that are grown in this area. Similarly, the higher levels of lead concentration observed at other sampling points within the study area (though not so much extensive farming occurs), could still be of concern especially that backyard gardens, where people grow various vegetables, are a common feature in these areas.

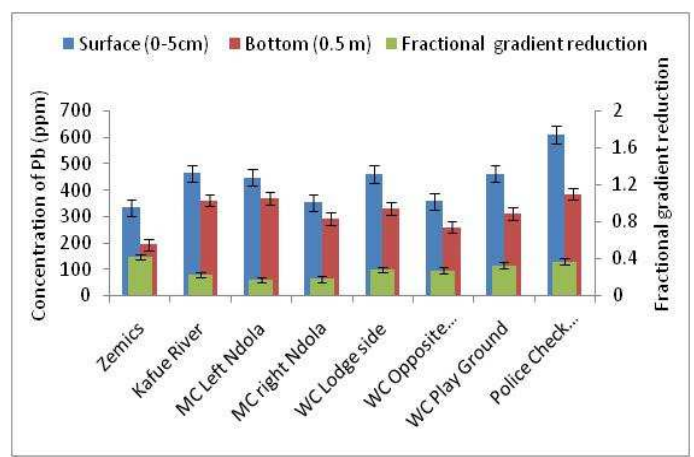

Figure 3: Vertical gradient variation close $(5 \mathrm{~m})$ to the HWY. The error bars are standard deviation of three replicates

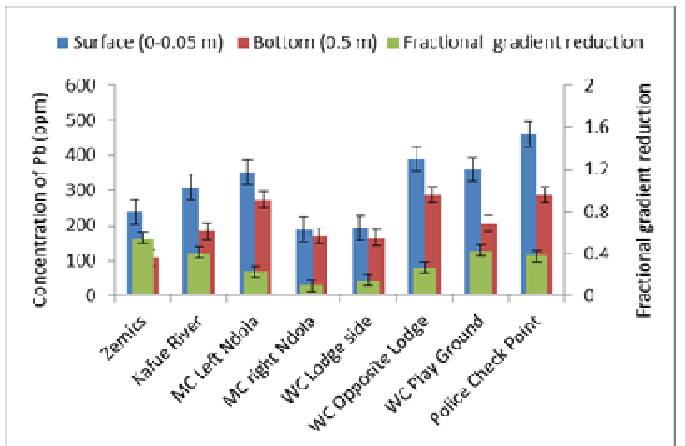

Figure 4: Vertical gradient variation $50 \mathrm{~m}$ away from HWY. The error bars are standard deviation of three replicates 


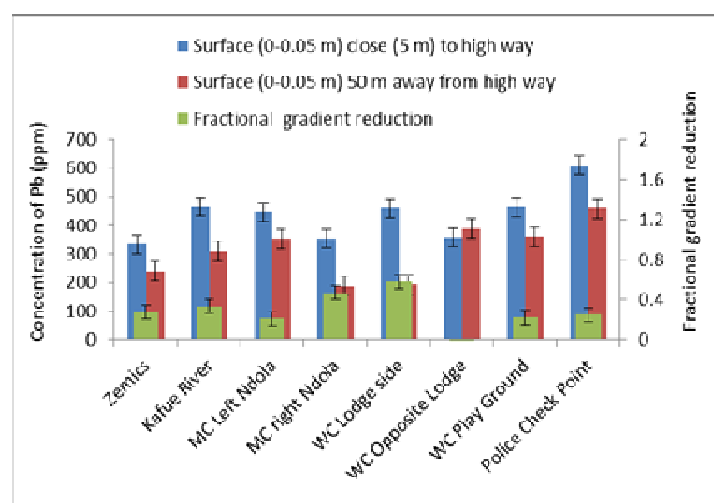

Figure 5: Horizontal gradient variation for surface $(0.05 \mathrm{~m})$ samples 5 and $50 \mathrm{~m}$ away from $H W Y$. The error bars are standard deviation of three replicates

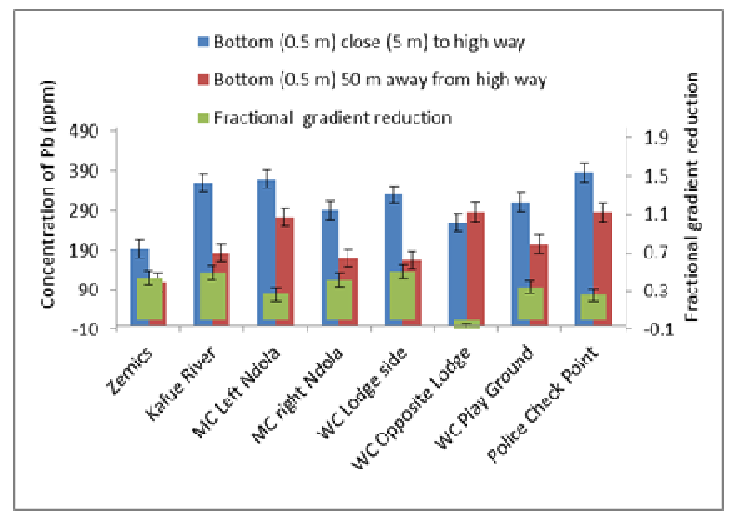

Figure 6: Horizontal gradient variation for bottom $(0.50 \mathrm{~m})$ samples 5 and $50 m$ away from HWY. The error bars are standard deviation of three replicates

Although, it has been argued thatlead could be strongly adsorbedon to organic matter in soils and consequently not subject to leaching except under acidic conditions[14], it is quite obvious that such strongly adsorbed lead may enter surface waters as a result of erosion of lead-containing soil particulates. This is particularly the case in the study area where, the soils are without grass cover for a larger part of the year, making them susceptible to both water and wind erosions [15]. Furthermore, soils contain micro and macroorganisms that release exudates that help in the breakdown of large organic matter molecules [15] and may help plants in the absorption of nutrients, including lead trapped by organic particulates. In fact, some researchers have reported that significant amounts of lead may be taken up in edible plants from the soil via the root system, by direct foliar uptake and translocation within the plant, and by surface deposition of particulate matter [16]. The exposure of people through the vegetables from their backyard gardens in the study area was therefore highly likely. However, to be certain about the likelihood of lead exposure of people in the study area, it would be necessary to study the soil factors such as cation exchange capacity, $\mathrm{pH}$, amount and the type of organic matter present and soil moisture content, as these factors affect the bioavailability of lead to vegetable plants [17].But these factors were not studied as they were outside the scope of this study.

Interestingly, others contend that lead from motor vehicles may have very limited mobility and hence little chance of contaminating sub-surface waters [18]; [19]. This is attributed to the fact that lead bromochloride, the primary form of lead emitted from motor vehicles, which once burned leaded gasoline in the presence of organohalogen scavenger compounds, are converted to the less soluble lead sulfate either by reactions in the atmosphere or by reactions at the soil surface, thus limiting its mobility in soil.

The overall results of this study were consistent with the findings of other researchers, who found that the concentration of lead in surface soils are generally higher than the lead concentration in the sub-surface, and that the concentration of soil lead generally decreases as distance from contaminating sources increases[19]. According to [19], the estimated lead levels in the upper layer of soil beside roadways are typically $30-2,000 \mu \mathrm{g} / \mathrm{g}(30-2000$ $\mathrm{ppm}$ ) higher than natural levels, although these levels drop exponentially up to $25 \mathrm{~m}$ from the roadway. In this study the surface lead concentrations ranged from $188 \mathrm{ppm}$ to $611 \mathrm{ppm}$.

\section{Conclusion}

The results of this study have shown that there has been an accumulation of lead in soils from the past use of leaded fuel. This was seen from the higher surface $(0.05 \mathrm{~m})$ concentrations which were in the range of $188-611 \mathrm{ppm}$ compared with the sub-surface $(0.50 \mathrm{~m}$ deep) concentrations which ranged from $109-386$ ppm.

The results, consistent with expectation, have shown that the concentration of lead reduced as the distance from the HWY increased. Based on the observed trend, the results from this study strongly suggest that the soil lead levels were influenced by airborne lead which came from motor vehicles. Therefore, it is the conclusion of this study that soils along the Kitwe-Ndola HWY have been contaminated due to accumulation of lead from the past use of leaded fuel in motor vehicles.

\section{Acknowledgements}

Special thanks to Chawezi Long we for all her efforts and the dedication in coordinating the sampling exercise and the logistics for all the period of this work.

\section{References}

[1] ERB, Energy Regulation Board Newsletter: Second Edition. ERB Lusaka, 2008.

[2] T. Midgley, Jr., and F. C. Kettering, Tetraethyl lead Solves the "Knock" Problem: Its Discovery and Early Developments OrganometallicsVol. 22: Issue 25, 2003, pp.5154-5178. 
[3] Christian Warren, Brush with Death, A social History of Lead Poisoning, John Hopkins University Press, BaltimoreUSA; 2001

[4] P.J. Landrigan, C.B. Schechter, J.M Lipton, M.C.Fahs, and J. Schwartz, "Environmental pollutants and disease in American children". Environmental health perspectives, Vol.110: Issue 7; 2002, pp.721-8.

[5] SADC, Phase out of Leaded Petrol: The Future of Petrol in Zambia. ERB, Lusaka, 2008.

[6] Mwila Mundu, Pollution in the Southern African Development Community (SADC) Region: The case of lead in Zambia and South Africa, National Graduate Institute for Policy Studies (GRIPS), Japan. 2010.

[7] UNEP, Sub-Saharan Africa Lead Matrix: Partnership for Clean Fuels and Vehicles, UNEP, Nairobi, 2009.

[8] R. Taylor, "Countries where Leaded Petrol is Possibly Still Sold for Road Use". The LEAD Group.http://www.lead.org.au/fs/fst27.html.2011 (Accessed, 13 May 2013).

[9] M.J, Kosnett, K.L. Hipkins, and B.L Materna, Medical guidelines for the lead-exposed worker. American Association Occupational Health Nurse: Vol., 46: 1998: pp330-339.

[10] M.J.Kosnett, Heavy metal intoxication and chelators. McGraw-Hill Professional, 2007.
[11] J.Eisinger, "Lead and wine. Eberhard Gockel and the colica Pictonum". Medical history Vol. 26; issue 3: 1982, pp.279302.

[12] E.Rossi, "Low Level Environmental Lead Exposure - A Continuing Challenge "The Clinical biochemist. Reviews / Australian Association of Clinical Biochemists Vol 29: Issue 2, 2008, pp.63-70.

[13] S. Gilbert and B. Weiss"A rationale for lowering the blood lead action level from 10 to $2 \mu \mathrm{g} / \mathrm{dl}$ " Neurotoxicology Vol. 27; Issue 5: 2006; pp.693-701.

[14] J.M. Pearce, "Burton's line in lead poisoning", European Neurology, Vol. 57: Issue 2, 2007, p118-9.

[15] W. M. White, Composition of the Oceanic Crust, Geochemistry, Vol. 3, 2013, pp. 564- 583

[16] R.C.Dart, Medical Toxicology, 3rd edition.Lippincott Williams \& Wilkins,2004.

[17] MECA, The Case for Banning Lead in Gasoline, Manufacturers of Emission Controls Association, Washington DC, 2003.

[18] J.C.Merrill; J.J.P Morton and S.D Soileau, Principles and Methods of Toxicology, Vol. 5 edition.CRC Press. 2007.

[19] L. Patrick, "Lead toxicity, a review of the literature. Part 1: Exposure, evaluation, and treatment". Alternative medicine review: a journal of clinical therapeutic, Vol. 11 Issue 1, 2006, pp2-22. 